Note

\section{Inhibition Study of Tyrosinase from Aspergillus oryzae}

\author{
Tomoaki TANAKA, ${ }^{* \dagger}$ Michio TAKEUCHI* \\ and Eiji ICHISHIMA ${ }^{\dagger \dagger}$ \\ Department of Agricultural Chemistry, \\ Tohoku University, \\ 1-I Tsutsumidori-Amamiyamachi, \\ Sendai, Miyagi 981, Japan \\ * Laboratory of Enzymology and Microbial Chemistry \\ Tokyo University of Agriculture and Technology, \\ Fuchu, Tokyo 183, Japan
}

Received August 24, 1988

Tyrosinase (monophenol, dihydroxy-L-phenylalanine: oxygen oxidoreductase, EC 1.14.18.1) is a copper-containing monooxygenase catalyzing both o-hydroxylation of monophenols and oxidation of $o$-diphenols to o-quinones. ${ }^{1)}$ Lerch $^{2}$ established, through work on Neurospora crassa tyrosinase, that it contains two copper ions per active subunits. However, the biochemical characterization of the reactions involved in the synthesis of melanin from tyrosine by tyrosinase has not yet been completed

Our previous paper described the isolation of three molecular forms (I $\sim$ III) of protyrosinase and catalytically active tyrosinases $(\mathrm{I} \sim \mathrm{III})$ from fresh mycelia of Aspergillus oryzae RIB-128. ${ }^{3)}$ This study was undertaken to describe the inactivation kinetics by mimosine, tropolone, kojic acid, and benzoic acid using Aspergillus oryzae tyrosinase $I$ as the enzyme source

Kojic acid (Lot M5B 4023) and diethyldithiocarbamate (Lot V5A 9293) were purchased from Nacalai Tesque, Inc. Benzoic acid (Lot 142752) was obtained from Kokusan Chemical Co. p-Aminobenzamidine hydrochloride (Lot FC 101), 3-monoiodotyrosine (Lot A-101), 3,5-diiodotyrosine (Lot AW 01), tyroxine (Lot AP02), $\alpha$-methyl-L-DOPA (Lot AW 01), 5-hydroxytryptophan (Lot AN01), and protocatechuic acid (Lot AW 01) were from Tokyo Kasei Co. L-Mimosine (Lot 112F-8110), tropolone (Lot 45F-0180), D-tyrosine (Lot 94F-0384), and D-DOPA (Lot 104C01941 ) were from Sigma, St. Louis, MO, USA. $\alpha$-MethylDL-tyrosine methylester was from Research Organic Co., Cleveland, Ohio, USA.

Purification of protyrosinase was done by the method in a previous paper. ${ }^{3)}$ The major band of protyrosinase I was extracted from polyacrylamide gel electrophoresis with $0.5 \mathrm{~mm}$ phosphate buffer, $\mathrm{pH} 6.0$, by the method of Kobayashi et al. ${ }^{41}$

The protyrosinase I was activated by incubation with an acidic buffer at $\mathrm{pH} 3.0$ and $0^{\circ} \mathrm{C}$ for $30 \mathrm{~min}$, as in our previous paper. ${ }^{3)}$ The reaction mixture consisted of $200 \mu 1$ of $0.2 \mathrm{M}$ sodium acetate $\mathrm{HCl}$ buffer at $\mathrm{pH} 3.0$ and $50 \mu \mathrm{l}$ of protyrosinase solution. After $30 \mathrm{~min}$ at $0^{\circ} \mathrm{C}$ the activation reaction was stopped by adding $3 \mathrm{ml}$ of $0.5 \mathrm{M}$ phosphate buffer, $\mathrm{pH}$ 6.0. The activated tyrosinase I was homogeneous by polyacrylamide gel electrophoresis. The polyacrylamide gel electrophoresis ${ }^{5)}$ was done using $7.5 \%$ polyacrylamide gel in Tris-glycine buffer $\mathrm{pH}$ 9.4. The protein was stained with Coomassie brilliant blue G-250.

For tyrosinase measurement, $2 \mathrm{ml}$ of $25 \mathrm{mM} \mathrm{L}$-DOPA solution was added to $3 \mathrm{ml}$ of the activated tyrosinase solution described above. After $5 \mathrm{~min}$ at $30^{\circ} \mathrm{C}$, tyrosinase activity in the reaction mixture was measured spectrophotometrically at $475 \mathrm{~nm}$ in a Shimadzu model UV 200 spectrophotometer. One enzyme unit (katal) was defined as the amount transforming $1 \mathrm{~mol}$ of L-DOPA per sec at $30^{\circ} \mathrm{C}$ and $\mathrm{pH} 6.0$.

The values of $K m$ and $k_{\text {cat }}$ were found graphically from Lineweaver-Burk plots. The $K i$ value was calculated from Dixon plots. ${ }^{6)}$

For L-DOPA oxidation at $\mathrm{pH} 6.0$ with the tyrosinase 1 from Aspergillus oryzae, a $K m$ value of $2.3 \mathrm{~mm}$, a $k_{\text {cat }}$ value of $4,500 \mathrm{sec}^{-1}$, and a $k_{\text {cat }} / K m$ value of $1,957 \mathrm{sec}^{-1} \mathrm{~mm}^{-1}$ were calculated.

Ohba et $a l^{\text {?) }}$ identified L-DOPA and protocatechuic acid as main precursors of the pigment of brown-rice koji. Haneda et al. ${ }^{8)}$ reported that L-DOPA can be synthesized effectively from L-tyrosine under acidic conditions ( $\mathrm{pH} 2$ to 5) by Aspergillus oryzae.

Effects of various reagents on the oxidase activity of tyrosinase I from Aspergillus oryzae at $\mathrm{pH} 6.0$ were observed. Metal-chelating reagents, diethyldithiocarbamate (DDC) and tropolone, were effective inhibitors of the tyrosinase from Aspergillus oryzae, suggesting that the tyrosinase is a metal-containing enzyme. Since this compound has been known to bind with $\mathrm{Cu}^{2+}$ at the active site of Vibrio tyrosinase, ${ }^{9}{ }^{9}$ the same mechanism of inhibition is suggested. But ethylenediamine tetraacetate (EDTA) and $o$-phenantroline had no inhibitory effect on the tyrosinase activity.

The tyrosinase was strongly inhibited by substrate analogues, kojic acid, mimosine, and benzoic acid. Protocatechuic acid, tryptophan, and 5-hydroxytryptophan were weak inhibitors for the tyrosinase. D-DOPA, x-methyl-L-DOPA, 3-monoiodotyrosine, 3,5-diiodotyrosine, $\alpha$-methyltyrosine methylester, and thyroxine had no inhibitory action.

A dixon plot of the tyrosinase with mimosine as an

$\dagger$ Present address: Basic Research Laboratories of Kewpie Co., Ltd., Sumiyoshi-cho, 5-13-1, Fuchu-shi, Tokyo 183, Japan.

†† To whom correspondence should be addressed. 
inhibitor showed a competitive inhibition. The value of the inhibitor constant, $K i$, for mimosine was $0.13 \mu \mathrm{m}$. Competitive inhibitions were also observed with tropolone, koji acid, and benzoic acid, and the $K i$ values were $0.22 \mu \mathrm{M}, 12 \mu \mathrm{M}$, and $700 \mu \mathrm{M}$, respectively.

Among the substrate-analogues mimosine, kojic acid, and benzoic acid, mimosine was the strongest inhibitor for the tyrosinase. Mimosine is an amino acid analogue isolated from certain plants belonging to the two legume genera, Mimosa and Leucaena. It is structurally related to 3,4-dihydroxy-L-phenylalanine (L-DOPA) and is toxic to various animals. ${ }^{10 \text { ) }}$

In comparison with the kinetic parameters of the tyrosinases, the tyrosinase I from Aspergillus oryzae had about 3-fold larger value of $\mathrm{Km}$, and a 14-fold higher value of $k_{\text {cat }}$ than those of Neurospora carassa tyrosinase. ${ }^{11}$ The $k_{\text {cal }} / \mathrm{Km}$ value of the tyrosinase from Aspergillus oryzae ${ }^{3}$ was about 4.3-fold higher than that of Neurospora crassa tyrosinase and about 2.3 -fold higher than that of mushroom tyrosinase. ${ }^{12)}$

Gutteridge and Robb ${ }^{11)}$ showed with Neurospora tyrosinase that the nature of the inhibition of benzoic acid was competitive with respect to $o$-diphenol, but that it was a mixed inhibitor of oxygen. Cyanide, which behaved as a reversible inhibitor under the assay conditions, was found to be a competitive inhibitor of oxygen and a noncompetitive inhibitor of $o$-diphenol

The nature of the inhibition exerted by benzoic acid on mushroom tyrosinase was reported by Duckworth and Coleman. ${ }^{12)}$ Benzoic acid was competitive with catechol. A $K i$ value of $1.02+0.17 \mu \mathrm{M}$ was found. They suggested that two separate substrate-binding sites exist within the active center, one for the catechol site and one for oxygen. Benzoic acid competes for the catechol site, while cyanide interacts with the oxygen site. ${ }^{\text {i2) }}$

Saruno et al. ${ }^{13)}$ mentioned that exposure of a tyrosinase from mushroom to a high concentration of kojic acid resulted in loss of activity.
Acknowledgment. This work was supported in part by a Grant-in-Aid for Scientific Research from the Foundation for Promotion of Food Science and Technology.

\section{References}

1) B. G. Malmstrom, in "Annual Review of Biochemistry," Vol. 51, ed. by E. E. Snell, Annual Review Inc., Palo Alto, California, 1982, pp. $21 \sim 59$.

2) K. Lerch, FEBS Lett., 69, 157 (1976).

3) E. Ichishima, H. Maeba, T. Amikura and H. Sakata, Biochim. Biophys. Acta, 786, 25 (1984).

4) M. Kobayashi, N. Hiura and K. Matsuda, Anal. Biochem., 145, 351 (1985).

5) O. Gabriel, in "Methods in Enzymology," Vol.22, ed. by W. B. Jakoby, Academic Press, New York, 1971, pp. 565 578.

6) M. Dixon and E. C. Webb, in "Enzymes," Academic Press, New York, 1960, p. 54.

7) T. Ohba, H. Murakami and S. Hara, Agric. Biol. Chem., 35, 674 (1971)

8) K. Haneda, S. Watanabe and I. Takeda, Appl. Microbiol., 22, 721 (197I).

9) S. H. Pomerantz and V. V. Murthy, Arch. Biochem. Biophys., 160, 73 (1974).

10) L. Fowden, D. Lewis and H. Tristran, in "Advances in Enzymology," Vol. 29, ed. by F. F. Nord, Interscience Publishers, John Wiley \& Sons, New York, 1967, pp 89 163.

11) S. Gutteridge and S. Robb, Eur. J. Biochem., 54, 107 (1975).

12) H. W. Duckworth and J. E. Coleman, J. Biol. Chem., 245, $1613(1970)$

13) R. Saruno, F. Kato and T. Ikeno, Agric. Biol. Chem., 43, 1337 (1979) 